\title{
El camino freudiano en la interpretación de los sueños de Luis Buñuel
}

\author{
Palabras clave: Surrealismo - Sigmund Freud — interpretación de los sueños \\ — onirismo - Luis Buñuel.
}

\section{Resumen}

En sus memorias, Luis Buñuel rechaza la interpretación de sus películas a través de la lente de las teorías de Sigmund Freud, subrayando su insuficiente capacidad para abarcar el vasto horizonte simbólico de su obra artística. El objetivo de este artículo es demostrar que, a pesar de la reticencia del director a la interpretación de base freudiana, es, de hecho, un terreno fértil para un análisis profundo y lógico de sus películas. La comparación de algunas teorías de Freud con los motivos oníricos presentes en todos los períodos de la obra de Buñuel revela un amplio espectro de relaciones entre el sueño, el surrealismo y las teorías de Freud. Además, esta interpretación facilita la comprensión adecuada del desarrollo de los protagonistas, así como la comprensión de las historias contadas.

\section{Introducción}

Si bien las referencias freudianas se consideran propias del arte surrealis$\mathrm{ta}^{1}$, Luis Buñuel, cineasta clave de la corriente, las declara poco satisfactorias para la interpretación de los sueños retratados en su obra. Opta por "evitar el aspecto racional explicativo que suelen tener" se sienta obligado a seguir un camino previsto ${ }^{3}$. Sin embargo, su inclinación a intercalar motivos oníricos llenos de símbolos y paradojas atribuye un sen-

1 W. Rojas, Cronología del movimiento surrealista, Santiago, Ediciones Universidad Católica de Chile, 2012, p. 34.

${ }^{2}$ L. Buñuel, Mi último suspiro, Barcelona, Debolsillo, 2008, p. 40.

3 J.M. Pardo, Luis Buñuel: Entre los sueños y la pesadilla, Bogotá, Panamericana Editorial, 2006, p. 107. 
tido importante a la Interpretación de los sueños, de Sigmund Freud ${ }^{4}$, cuyo enfoque se convierte en una herramienta indispensable para comprender las creaciones de Buñuel. Su psicoanálisis contribuye en particular a demarcar la frontera entre lo onírico y lo real, y a establecer el impacto de las alucinaciones nocturnas sobre el desarrollo de los protagonistas ${ }^{5}$.

En el cine de Buñuel "los sueños desempeñan un importantísimo papel, permitiendo el libre flujo de las imágenes y su asociación irracional, en la mejor tradición surrealista" 6 . El director menciona que algunos de los elementos aplicados en sus películas surgen de su propia experiencia nocturna ${ }^{7}$. Por otro lado, la posibilidad de realizar las escenas oníricas le anima a adaptar las novelas de otros creadores ${ }^{8}$. Su sueño sirve como instrumento indispensable para librarse de las convicciones fijas y crear imágenes grotescas 9 .

A través de una interpretación freudiana de las visiones oníricas retratadas en su cine, este trabajo intenta presentar una cierta inseparabilidad de Freud y Buñuel, pese a la negación del director. Por motivos de espacio, el análisis siguiente está basado en tres películas en las que la coincidencia de ambos creadores parece ser más evidente: Los olvidados, Tristana y Bella de día. Todas las creaciones están inspiradas en otras obras: Bella de día es la adaptación de la novela de Joseph Kessel ${ }^{10}$; Tristana, de la novela del mismo título de Benito Pérez Galdos, mientras que Los Olvidados hacen clara referencia a El limpiabotas, de Vittorio de Sica ${ }^{11}$. La selección de las escenas de sueño concuerda con la importancia que en sus recuerdos les atribuye el mismo director. Por último, a pesar de la riqueza de su simbolismo, que permitiría abrir nuevos paradigmas interpretativos, el artículo se centra exclusivamente en los elementos más vinculados al camino freudiano.

\section{La interpretación de los sueños}

Las teorías expuestas por Freud en el tratado La interpretación de los sueños (1899) sirven de gran inspiración a los surrealistas ${ }^{12}$, que se consideran a sí mismos los descubridores del sentido oculto bajo el sueño, comprendido

${ }^{4}$ E. Królikowska, Śladami Buñuela: kino hiszpańskie, Kraków, Centralny Ośrodek Metodyki Upowszechniania Kultury, 1988, p. 76.

5 J.M. Pardo, op. cit., p. 14.

6 A. Sánchez Vidal, "Cine, el burdel de los sueños", en: El surrealismo y el sueño, Madrid, Educathyssen, 2013, p. 100

7 P. Illie, Los surrealistas españoles, Madrid, Taurus, 1972, p. 68.

${ }^{8}$ L. Buñuel, op. cit., p. 79.

9 J.M. Pardo, op. cit., p. 113.

${ }_{10}$ L. Buñuel, op. cit., p. 205.

11 E. García Riera, Historia del cine mexicano, Ciudad de México, Secretaría de Educación Pública, 1986, p. 152.

12 F. Bradley, Surrealismo: movimientos en el arte moderno, Madrid, Ediciones Encuentro, 2001, p. 38. 
como la "más amplia fuente de conocimiento"13. La importancia particular concedida a las visiones nocturnas es debida a su falta de límites, su impacto sobre el comportamiento consciente y, en definitiva, a lo ilógico de su estructura. Lo onírico surge a través de la liberación de la mente de las conveniencias sociales ${ }^{14}$.

Freud considera el sueño el "resultado de una actividad intelectual altamente complicada" que, como tal, debe "ser incluido en el conjunto de actos comprensibles de nuestra vida despierta"15. Sus investigaciones se focalizan ante todo en la sexualidad y las inclinaciones eróticas del durmiente, escondidas en su subconsciencia ${ }^{16}$. En su tratado predomina una cierta inflexibilidad relacionada con el análisis de la identidad sexual, basada en la teoría de que los elementos femeninos o masculinos durante el sueño cambian al revés su significado ${ }^{17}$. A su parecer, la mayoría de las visiones aluden a los trastornos sexuales, especialmente cuando los deseos reflejados durante la noche son imposibles de cumplir o resultan embarazosos pero, al mismo tiempo, deseables. En lo que se refiere a este impedimento, "tiene que tratarse de una volición que fue susceptible alguna vez de desarrollar libido, o sea de un impulso sexual"18. Las inclinaciones sexuales, exteriorizadas con frecuencia en forma de pesadilla, o de la así denominada "deformación onírica", suelen estar ocultas por su inconveniencia social o moral (como tales Freud indica ante todo el masoquismo o el complejo de Edipo $)^{19}$. La facilidad con la que el durmiente se despierta, tiene su raíz en la convicción de que hay que pagar por sus acciones. El precio de los deseos es muy alto; por eso el durmientese despierta de una manera repentina, a causa del subconsciente sentimiento de culpabilidad ${ }^{20}$.

El sentido verdadero del sueño pasa por los mecanismos internos de censura que tienden a "imponer a los elementos que aspiran a llegar a la conciencia aquellas transformaciones que le parecen convenientes" 21 . Para llegar a comprenderlo, hay que renunciar a su sentido literal, ya que lo esencial de una visión onírica está oculto en los símbolos arraigados en la cultura, cuya dualidad hace difícil la interpretación. Para entenderlos hay que "emplear una técnica combinada que se apoya, por un lado, en las asociaciones del sujeto, y completa, por otro, la interpretación con el conocimiento que el interpretador posee del simbolismo"22; es decir, uno de los recursos favoritos de Buñuel:

\footnotetext{
13 A. Breton, Manifiestos del surrealismo, Buenos Aires, Argonauta, 2001, p. 36.

14 Ibidem, p. 29.

15 S. Freud, La interpretación de los sueños, Madrid, Biblioteca Nueva, 2000, p. 82.

16 Ibidem, p. 88.

17 Ibidem, p. 308.

18 Ibidem, p. 291.

19 Ibidem, p. 89.

20 Ibidem.

21 Ibidem, p. 93.

22 Ibidem, p. 303.
} 
encadenar, entrelazándolos, elementos de la vida diurna de sus protagonistas con elementos de un particular valor simbólico ${ }^{23}$.

\section{Los olvidados}

La película Los olvidados (1950) retrata la vida de Pedro, un gamberro joven, privado de su infancia y enredado involuntariamente en el asesinato de uno de sus compañeros, Cacarizo. Durante la película el protagonista principal sueña dos veces. La primera visión, considerada una de las escenas más importantes en la historia del cine hispano ${ }^{24}$, se estructura como un complejo terreno de análisis freudiano. La escena comienza con el cacareo de una gallina blanca, que, según algunos investigadores, subraya el matiz erótico de la visión ${ }^{25}$. Debajo de la cama Pedro ve a su compañero asesinado, ensangrentado y con una risa grotesca. Su madre se despierta con una cara risueña y le reprocha su mal comportamiento de una manera cariñosa, preguntándole por el crimen: sabe de su pecado, pero no lo reprende. El niño se justifica, y con lágrimas y la voz temblorosa se lamenta de la falta de amor materno. La mujer no le hace caso, quejándose del cansancio y mostrándole sus manos destruidas. Aunque se oyen sus palabras, su boca permanece cerrada, como si su entera creación fuera nada más que una imaginación del niño. Pedro promete enmendarse y ayudar en casa; sin embargo, quiere conocer la razón por la que el otro día la madre le negó la comida. Al son del trueno, la mujer le otorga un trozo de carne cruda; sin embargo Jaibo, el asesino y su Némesis, se lo arranca a Pedro de debajo de la cama.

La imaginación del muchacho idealiza y embellece la visión de su madre, en realidad una mujer escabrosa y primitiva. Según Freud, el motivo de los padres en el sueño infantil está indisolublemente relacionado con el complejo de Edipo $^{26}$. En cambio, la forma de una pesadilla está relacionada con una deformación onírica, que esconde un deseo verdadero, pero imposible en las imágenes espantosas ${ }^{27}$. La madre de Pedro constituye su objeto de deseo irrealizable a causa del incesto. En la visión ambos desempeñan los papeles propios de una relación romántica: ella se comporta de una manera coquetona, mientras él quiere ser el único hombre protector en su mundo. En el sueño faltan los hermanos del chico, aunque durante el día la casa está llena de niños. La atracción y la repulsión que el protagonista siente hacia su madre, están enfatizadas por el motivo de la carne cruda: asqueroso, por un lado; por otro, deseado por un we, 1985.

${ }^{23}$ K. Janicka, Światopogląd surrealizmu, Warszawa, Wydawnictwa Artystyczne i Filmo-

24 E. García Riera, op. cit., p. 154.

25 I. Kolasińska-Pasterczyk, "Kino meksykańskie", en: T. Lubelski, I. Sowińska, R. Syska (eds.), Kino klasyczne, Kraków, Universitas, 2011, pp. 98-111.

26 S. Freud, op. cit., p. 96.

27 Ibidem. 
chico hambriento. Algunos investigadores indican que la imagen de la madre hace referencia a la Madre de Dios de tipo mediterráneo, que une tres personalidades: la Virgen, la Madre y la Esposa ${ }^{28}$. Pedro las necesita a todas; sin embargo, a lo largo del sueño la madre demoníaca sustituye a la madre divina.

Según Freud, la alucinación nocturna deriva de las experiencias diurnas, reflejadas de una manera franca y directa ${ }^{29}$. La visión del mundo, representada por la mente de Pedro, es todavía muy infantil. El sueño muestra su necesidad más profunda: el amor materno y el sentimiento de pertenencia. Así pues, la brutalidad de la escena con la carne demuestra su hambre tremenda, tanto física como emocional. El motivo de quitarle el trozo simboliza su miedo a ser rechazado y sustituido por Jaibo, que pronto se convierte en su rival, tratando de seducir a su madre. El primer sueño consigue unir todos los factores que le preocupan al protagonista principal e influyen sobre sus decisiones. El día después de la pesadilla, Pedro decide cambiar su vida y emplearse en una herrería, convirtiéndose en una parodia de un adulto responsable. Con su visión termina la ingenuidad y la inocencia infantil. El sueño le permite empezar una nueva vida, sirviendo de un tipo de catarsis: si bien ha participado en un crimen, está absuelto gracias a una ingenua promesa de enmendarse.

La segunda alucinación tiene su origen en los miedos infantiles y las advertencias de los mayores. Después de huir de casa, Pedro sueña con una urbe nocturna con las calles alumbradas. Allí, delante de un escaparate, el niño accede a una propuesta evidentemente indecente de un señor mayor, que le muestra dinero. Al encontrar a un policía, Pedro escapa, presa del pánico. Siguiendo el hilo freudiano, bajo la capa del impedimento está escondido un deseo. Si bien al inicio el muchacho expresa una aversión, al final acepta la invitación. Su reacción repentina a la aparición del guarda indica que, aunque en el fondo de su alma Pedro siente atracción hacia otras personas de su sexo, es consciente de que en su sociedad su orientación sexual tendría como consecuencia el ostracismo, por tratarse de un crimen prohibido por la ley tradicional. La propuesta inmoral del desconocido le pone al nivel de un delincuente. Los mecanismos censorios están inculcados en su psiquismo hasta tal punto que aun durmiendo se castiga por sus inclinaciones. Expulsado de su pueblo y su familia, se considera a sí mismo totalmente depravado.

Por otro lado, Freud establece una cierta sostenibilidad de los elementos masculinos y femeninos ${ }^{30}$. Desde este punto de vista, el hombre mayor encarna una nostalgia infantil por un protector adulto, supuestamente la madre. El carácter doble del personaje (por un lado, un ser preocupado; por otro, un hombre perverso) alude de nuevo al complejo de Edipo, predominante en las relaciones entre el protagonista y su madre. Merece la pena mencionar que antes de la aparición del desconocido, Pedro está contemplando un escaparate

28 E. García Riera, op. cit., p. 34.

29 S. Freud, op. cit., p. 82.

30 Ibidem, p. 308. 
de una tienda lujosa. Así pues, el dinero ofrecido por un hombre le serviría para satisfacer sus caprichos, ya que, en realidad, Pedro tiene sus necesidades básicas cubiertas: lo único que le falta es la presencia de otro ser humano preocupado por él. Sin embargo, su infancia ardua lo ha acostumbrado a pensar que el cariño maternal es una extravagancia inalcanzable para los delincuentes como él, un verdadero olvidado.

\section{Bella de día}

Belle de jour (1967) narra la historia de Severine y Pierre, un matrimonio joven. La protagonista principal no puede obligarse a mantener relaciones sexuales con su marido; sin embargo, al mismo tiempo, sus sueños revelan sus inclinaciones sexuales violentas. Poco después decide emplearse de prostituta en un prostíbulo, donde trabaja hasta que allí aparece un conocido suyo, Hussón.

Todos los sueños de la protagonista oscilan alrededor de su sexualidad perpleja, cuyo nivel de brutalidad aumenta con el desarrollo de la trama.Ya la primera escena de la película se muestra como una metáfora onírica de las preferencias de Severine. En su alucinación, el matrimonio está viajando en un carro conducido por dos lacayos. De improviso, Pierre pierde la paciencia por la frialdad de su mujer y ordena a los criados que la humillen y finalmente violen. Cuando el primer hombre se le acerca, la cara de la chica expresa placer.

Las inclinaciones al masoquismo de Severine adquieren mayor importancia en el contexto de las teorías freudianas. Según Freud, el placer que siente el destinatario de las prácticas sadistas reafirma el hecho de ser amado por el otro $^{31}$. Por consiguiente, las fantasías de la protagonista sobre el trato brutal de Pierre simbolizan su voluntad de asegurarse su amor. Al mismo tiempo, se siente incapaz de satisfacer las necesidades del marido, a no ser que estén ligadas con el sufrimiento físico y la humillación. El mismo impedimento demuestra en el prostíbulo, cuando uno de los clientes exige ser dominado: Severine no puede satisfacer sus requisitos. Su atracción fetichista por el dolor se muestra también en la visión que le atormenta después de la aparición de Hussón. En su sueño, Pierre y el mencionado personaje deciden batirse en duelo. Aunque se oyen los tiros, ambos hombres permanecen intactos; ella, en cambio, resulta herida. El cariño de su marido, mezclado con el dolor físico, parece darle alivio a Severine.

Por otro lado, la escena del duelo implica la lucha interna de la mujer: la Severine inocente está peleando con la Severine carente de principios morales. El que sale triunfante es Pierre, un símbolo de su vida diurna, por lo cual decide volver a su tranquila vida burguesa. Predomina su yo moral.

31 Ibidem, p. 129. 
La confusión sexual de Severine surge supuestamente de las experiencias de la niñez, cuando estaba acosada por su tío. Según Freud, cualquier trastorno de la sexualidad infantil produce perversiones o inhibiciones en la esfera sexual $^{32}$. Los remordimientos de conciencia por no haberse opuesto al opresor vuelven tras su primer día en la mancebía. Recuerda entonces su Primera Comunión, cuando se negó a abrazar el sacramento, aparentemente por haberse sentido indigna de él. Con este acto blasfemo empieza su decaimiento moral, que sigue profundizándose hasta el punto de que Severine no se sienta digna del amor de su marido.

Tampoco parece accidental la presencia de Hussón en los sueños. Aunque Severine le muestra desdén por su comportamiento frívolo, en realidad parece estar atraída por su machismo y su brutalidad, contrarios al carácter de su marido. Esta inclinación está reflejada en sus visiones, en las que Hussón lleva la delantera en humillarla, pese a la presencia de su marido. Severine protesta; sin embargo, aunque se oye su voz, sus labios permanecen inmóviles y en su cara aparece una expresión de voluptuosidad. Sus negaciones son exigidas por las reglas de la decencia; no obstante, no son sinceras.

Al final de la película Buñuel aplica uno de sus recursos favoritos: encadena las visiones de ensueño hasta imposibilitar la distinción entre lo real y lo onírico. La película termina cuando, tras una serie de visiones, Severine sale a la terraza, y allí, en lugar de la ciudad, aparecen el bosque y el carro de sus alucinaciones. Buñuel entrelaza su personaje en una espiral de visiones, por lo que no es posible demarcar una frontera clara entre sus fantasías y su vida diurna.

Desde el punto de vista freudiano, la película muestra el proceso de maduración emocional y sensual de Severine y el establecimiento de su identidad sexual, antes expresada solamente en los sueños. El carro, que aparece al final de la película, simboliza el desarrollo de sus preferencias eróticas, ya que la protagonista finalmente las deja entrar en la realidad. Las visiones simbolizan también un cierto clamor por la libertad personal, cuya falta es debida a las reglas fijas, impuestas por la sociedad burguesa. Lo que indigna a los otros (como el acto de prostituirse), a Severine la atrae, de una manera pérfida y obsesiva. Los castigos físicos que experimenta en sus visiones simbolizan el precio de la independencia. Los únicos momentos en que Severine parece estar de verdad viva y satisfecha, son los sueños o su trabajo en el prostíbulo.

\section{Tristana}

Tristana (1970) retrata una relación basada en la atracción y repulsión entre un tío (Don Lope) y su sobrina-esposa (Tristana). Durante la película aparecen

32 Ibidem. 
dos sueños de la protagonista principal, y en ambos se repite el motivo de la cabeza decapitada de don Lope. En su primera visión la chica está jugando con dos amigos y almorzando en la casa de un campanero. Luego suben al campanario y allí, en lugar del badajo de la campana, Tristana descubre la cabeza ensangrentada de su tío. Otro sueño aparece al final de la película, cuando la mujer ya está casada con don Lope. Esta vez su cabeza ensangrentada está balanceándose en el dormitorio, cerca del techo.

Las alucinaciones corroboran las teorías de Freud, relacionadas con la deformación onírica del deseo inconveniente y con el motivo de la muerte en los sueños. Según el camino freudiano, la visión del fallecimiento o del cadáver de una persona cercana alude a la voluntad de deshacerse de ella, bastante manifiesta en el caso de Tristana. La chica sueña con la decapitación de su tío y en la brutalidad de este óbito se refleja toda la intensidad de su anhelo de eliminarlo de su vida. La primera escena onírica lleva un mensaje de su subconsciencia: si don Lope estuviera muerto, ella recuperaría la libertad. Los otros elementos presentes en la escena (los chicos, el campanero, la comida) demuestran la pluralidad de su vida, todavía no limitada a su pariente. No obstante, cuando la mujer sueña por segunda vez, la cabeza de don Lope es lo único que ve. En este momento están casados y su voluntad de librarse del tío va creciendo. Por otro lado, el hombre está envejeciendo y su pronta muerte parece soterrada en la mente de Tristana. Lo que es más significativo es que, aunque el hombre ha cambiado físicamente, la cabeza ensangrentada tiene su cara de antes. El deseo permanece fuertemente arraigado en la mente de la protagonista desde sus tiempos de joven.

Después de ambas visiones, Tristana se despierta con espanto. Una de las teorías freudianas define la tristeza o el miedo provocados por un sueño como un producto del mecanismo de la censura interior ${ }^{33}$, que no le permite al adormecido enfrentarse sinceramente con sus sentimientos más profundos, ya que el precio de cumplir el deseo es demasiado alto. Esta es la razón verdadera del pavor de Tristana. Puesto que la posición social de ambos protagonistas es diferente y la chica le debe mucho a su tío, no está en situación de admitir que con gusto se liberaría de su cuidado. Aunque la presencia de don Lope siempre le fastidiaba (el hombre menciona que de pequeña lloraba al verlo), Tristana todavía no es consciente de sus antipatías. Las reconoce tras la segunda visión, cuando se despierta inquieta, pero no tanto como en el primer caso. Esta tranquilidad suya alude al odio, antes escondido profundamente en su subconsciencia. Tristana deja de sentirse obligada a su tío por su protección; al contrario, le echa la culpa de su vida infeliz. Los acontecimientos que siguen a la segunda visión, se corresponden con el motivo de la deformación onírica del deseo, escondido en la pesadilla: aunque don Lope está moribundo, la protagonista renuncia a llamar al médico y le deja morir.

33 Ibidem, p. 114. 
Merece la pena mencionar que en la primera escena onírica aparece otro hilo, explicable a través de las teorías freudianas. En la visión los compañeros de Tristana intentan subirle la falda, con una obvia intención sexual. Aunque la chica les echa una reprimenda categórica, la situación entera no le preocupa. Según Freud, el motivo erótico en el sueño está relacionado con el desarrollo de una inclinación al sadomasoquismo, todavía no consciente ${ }^{34}$. Por consiguiente, la indiferencia de Tristana indica que, por un lado, la protagonista todavía no ha llegado completamente a la pubertad, y por eso no asocia los juegos ambiguos con el sentimiento de vergüenza o rabia; por otro lado, le fascina la dominación sobre sus compañeros provenientes de una capa social más baja.

\section{Conclusiones}

A pesar de que Luis Buñuel rechaza la interpretación freudiana de su obra, el estudio revela un amplio panorama de referencias a Freud. El motivo de la deformación onírica y de los deseos ocultos en la subconsciencia aparece en todas las películas analizadas. Los sueños completan los acontecimientos diurnos, explicando la actitud de los protagonistas y contribuyendo a la comprensión de su desarrollo. Las visiones de Tristana retratan el odio hacia su marido, bien arraigado en la subconsciencia, por lo que contribuye a su muerte. La interpretación freudiana de Belle de jour muestra otra cara de la protagonista, justificando su frialdad e infidelidad con la búsqueda de la propia madurez sexual. Las visiones de Pedro, de Los olvidados, muestran que, pese a su voluntad de cambiar la vida, no es tan inocente como parece.

Algunas de las visiones avisan de los eventos futuros; otras constituyen la fuerza motriz de las decisiones de los durmientes, conforme a la opinión de Freud acerca del impacto del sueño sobre la vida diurna. Buñuel encadena las escenas oníricas hasta tal punto que resulta imposible indicar con claridad cuáles de los hechos pertenecen al mundo real y cuáles tienen el carácter de alucinación. Las visiones y lo real permanecen en una retroacción constante, ya que los sueños cierran la trama de la película en un corchete. Con la primera visión se aclaran los motivos de constreñimiento del protagonista, la otra presagia su pronta liberación. Así, pues, la primera escena onírica de Los olvidados muestra la tragedia de Pedro, rechazado por la sociedad y por su propia madre; la segunda precede a su muerte, que lo libera de la atrocidad de su mundo. Analógicamente, el principio de Belle de jour alude a las inhibiciones sexuales de Severine, la última visión muestra su conformidad con sus necesidades. Finalmente, el primer sueño de Tristana anuncia su relación trágica con don Lope, el segundo anuncia el pronto fallecimiento de su opresor.

34 Ibidem. 
Luis Buñuel es un director principal de la corriente surrealista, repleta de referencias al análisis de Freud. La heterogeneidad de su obra admite diversos hilos de interpretación; sin embargo, como se demuestra más arriba, el camino freudiano fructifica con unas conclusiones integrales y lógicas, que completan la recepción de su creación. Quizás Buñuel, un gran burlador ${ }^{35}$, rechace categóricamente las relaciones con la Interpretación de los sueños para invitar al espectador a un juego irónico, basado en el propio esfuerzo mental y la desconfianza artística.

\section{Referencias bibliográficas}

BRADLEY Fiona

2001 Surrealismo: Movimientos en el Arte Moderno, Madrid, Ediciones Encuentro.

BRETON André

2001 Manifiestos del Surrealismo, Buenos Aires, Argonauta.

BUÑUEL Luis

2008 Mi último suspiro, Barcelona, Debolsillo.

2012 Tristana, Varsovia, Klasyka Mayfly.

2012 Bella de día, Varsovia, Klasyka Mayfly.

2012 Los olvidados, Varsovia, Klasyka Mayfly.

ARANDA José Francisco

1975 Luis Buñuel, biografía crítica, Barcelona, Editorial Lumen.

FREUD Sigmund

2000 La interpretación de los sueños, Madrid, Biblioteca Nueva.

FUENTES Vctor

1993 Buñuel en México, Teruel, Instituto de Estudios Turolenses.

GARCÍA RIERA Emilio

1986 Historia del cine mexicano, Ciudad de México, Secretaría de Educación Pública.

ILLIE Paul

1972 Los surrealistas españoles, Madrid, Taurus.

JANICKA Krystyna

1985 Światopogląd surrealizmu, Warszawa, Wydawnictwa Artystyczne i Filmowe.

KOLASIŃSKA-PASTERCZYK Iwona

2011 “Kino meksykańskie”, en: Lubelski T., Sowińska I., Syska R. (eds.), Kino klasyczne, Kraków, Universitas, pp. 98-111.

KRÓLIKOWSKA Elżbieta

1988 Śladami Buñuela: kino hiszpańskie, Kraków, Centralny Ośrodek Metodyki Upowszechniania Kultury.

PALUMBO Federico

2012 L'ispirazione nel Surrealismo, Punta de Vacas, Parques de Estudio y Reflexión.

PARDO Jorge Manuel

2006 Luis Buñuel: Entre los sueños y la pesadilla, Bogotá, Panamericana Editorial. ROJAS Waldo

2012 Cronología del movimiento surrealista, Santiago, Ediciones Universidad Católica de Chile.

35 J. Francisco Aranda, Luis Buñuel, biografía crítica, Barcelona, Editorial Lumen, 1975, p. 23. 
SÁNCHEZ VIDAL Agustín

1991 Luis Buñuel, Madrid, Cátedra.

2013 "Cine, el burdel de los sueños", en El surrealismo y el sueño, Madrid, Educathyssen.

\section{The Freudian path in the interpretation of the dreams of Luis Buñuel} Buñuel.

Keywords: surrealism — Sigmund Freud — interpretation of dreams — onirism — Luis

\section{Abstract}

In his memoirs, Luis Buñuel rejects the interpretation of his films through the lens of the theories of Sigmund Freud, stressing their unsatisfactory ability to encompass the vast symbolic horizon of his artistic body of work. The aim of this article is to prove that despite the director's reluctance to the Freudian-based interpretation, it is, in fact, fertile ground for an in-depth and logical analysis of his pictures. The comparison of Freud's particular theories with oneiric motifs present across all periods of Buñuel's work reveals a wide spectrum of relations between dream, surrealism, and Freud's theories. Furthermore, such interpretation facilitates the proper understanding of the development of the protagonists as well as the understanding of the told stories.

Fecha de recepción: 6 de mayo de 2019

Fecha de aceptación: 21 de febrero de 2020 